excluded $^{6}$ and a recessive family in whom no linkage analysis had been undertaken. ${ }^{15}$

We agree with Shastry and Trese in that the variable phenotype observed in FEVR patients could well be due to modifying genes at other loci as well as environmental effects. However, to prove such a link, evidence must be presented showing that individuals containing two mutant alleles consistently have a different phenotype (either more severe or milder) than those with only one. The results presented by Shastry and Trese are interesting but anecdotal, since they provide no statistically significant evidence that factor V Leiden has an effect on the FEVR phenotype. We understand that the authors have very carefully worded their discussion so that they do not actually come to any conclusions about their finding and only suggest possibilities, but the fact that this cosegregation could be simply due to chance is not discussed. Indeed, the authors state that 'the cosegregation of unlinked genes in such a small family is statistically unlikely'. As we have shown, this statement is not supported by the data these authors presented. Furthermore, the lack of Leiden mutations in our FEVR patient cohort suggests that the factor V Leiden does not play a significant role in FEVR severity and that further studies are needed to dissect out the complexities of the variable phenotypes observed in FEVR patients.

\section{Acknowledgements}

This work was supported by The Royal Society, The Wellcome Trust and Yorkshire Eye Research.

$$
\begin{array}{r}
\text { Helen M Bottomley }{ }^{1} \text {, Louise M Downey }{ }^{1} \\
\text { Chris F Inglehearn }{ }^{1} \text { and Carmel Toomes }{ }^{*, 1} \\
{ }^{1} \text { Molecular Medicine Unit, School of Medicine, University of } \\
\text { Leeds, UK }
\end{array}
$$

${ }^{*}$ Correspondence: $\operatorname{Dr} C$ Toomes, Molecular Medicine Unit, Clinical Sciences Building, Level 6, St. James's University Hospital, Leeds, LS9 7TF, UK. Tel: +44113206 6612; Fax: +44113 2444475; E-mail: c.toomes@leeds.ac.uk

\section{References}

1 Shastry BS, Trese MT: Cosegregation of two unlinked mutant alleles in some cases of autosomal dominant familial exudative vitreoretinopathy. Eur J Hum Genet 2004; 12: 79-82.

2 Robitaille J, MacDonald MLE, Kaykas A et al: Mutant Frizzled-4 disrupts retinal angiogenesis in familial exudative vitreoretinopathy. Nat Genet 2002; 32: 326-330.

3 Chen ZY, Battinelli EM, Fielder A et al: A mutation in the Norrie disease gene (NDP) associated with X-linked familial exudative vitreoretinopathy. Nat Genet 1993; 5: 180-183.

4 Downey LM, Keen TJ, Roberts E, Mansfield DC, Bamashmus M, Inglehearn CF: A new locus for autosomal dominant familial exudative vitreoretinopathy maps to chromosome $11 \mathrm{p} 12-13$. Am J Hum Genet 2001; 68: 778-781.

5 Toomes C, Bottomley HM, Jackson RM et al: Mutations in LRP5 or FZD4 underlie the common FEVR locus on chromosome 11q. Am J Hum Genet 2004; 76: 721-730.

6 Toomes C, Downey LM, Bottomley HM, Mintz-Hittner HA, Inglehearn CF: Further evidence of genetic heterogeneity in familial exudative vitreoretinopathy; exclusion of EVR1, EVR3 and EVR4 in a large autosomal dominant pedigree. $\mathrm{Br} J$ Ophthalmol 2005; 89: 194-197.

7 Kondo H, Hayashi H, Oshima K, Tahira T, Hayashi K: Frizzled 4 gene (FZD4) mutations in patients with familial exudative vitreoretinopathy with variable expressivity. $\mathrm{Br} J$ Ophthalmol 2003; 87: 1291-1295.

8 Toomes C, Bottomley HM, Scott S et al: Spectrum and frequency of FZD4 mutations in familial exudative vitreoretinopathy (FEVR). Invest Ophthalmol Vis Sci 2004; 45: 2083-2090.

9 Rees DC, Cox M, Clegg JB: World distribution of factor V Leiden. Lancet 1995; 346: 1133-1134.

10 Ridker PM, Miletich JP, Hennekens $\mathrm{CH}$, Buring JE: Ethinic distribution of factor $\mathrm{V}$ Leiden in 4047 men and women. JAMA 1997; 277: 1305-1307.

11 Koster T, Rosendaal FR, de Ronde H, Briet E, Vandenbroucke JP, Bertina RM: Venous thrombosis due to poor anticoagulant response to activated protein C: Leiden Thrombophilia Study. Lancet 1993; 342: 1503-1506.

12 Braun A, Muller B, Rosche AA: Population study of the G1691A mutation (R506Q, FV Leiden) in the human factor $\mathrm{V}$ gene that is associated with resistance to activated protein C. Hum Genet 1996; 97: 263-264.

13 Schroder W, Koessling M, Wulff K, Wehnert M, Herrmann FH World distribution of factor V Leiden mutation. Lancet 1996; 347: $58-59$.

14 Toomes C, Downey LM, Bottomley HM et al: Identification of a fourth locus (EVR4) for familial exudative vitreoretinopathy (FEVR). Mol Vis 2004; 10: 37-42.

15 Downey LM, Sheridan E, Bradbury J, Inglehearn CF, Toomes C: Autosomal recessive inheritance of familial exudative vitreoretinopathy. Invest Ophthalmol Vis Sci 2004; 45 (Suppl): 4760.

\title{
Reply to Bottomley et al
}

European Journal of Human Genetics (2006) 14, 7-8. doi:10.1038/sj.ejhg.5201518; published online 16 November 2005

We welcome additional studies by Dr Bottomley et al on factor V Leiden mutation in other FEVR families and happy to note that they find our report 'interesting'. However, it is not surprising that they did not find additional families containing this mutation in their cohort. We have discussed in our short report most of the limitations of our study mentioned by Bottomley et al in their comments. Additionally, as correctly stated by Bottomley et al, we have not claimed the effect of mutation on phenotype or its association in other FEVR families but we speculated and 
hypothesized that similar thing could be involved in variable phenotype. For instance, we discussed that such digenic mutation is not widespread (abstract), segregation observed is suggestive of linkage or unlikely (discussion), there is no correlation between the genotype and phenotype (discussion), FZD4 mutation alone is sufficient to cause a severe phenotype in other families (discussion) and lack of functional studies or availability of proper patients to understand the contribution of Leiden mutation in the presence of FZD4 gene mutation (discussion). In addition, we are aware of the fact that $5 \%$ of the population contains Leiden mutation, but it still does not address the question why only the affected individuals in the family have the mutant allele and not the unaffected individuals? Finally, we do agree that further studies are needed to understand the variable phenotypes in FEVR patients.

Barkur S Shastry and Michael T Trese Department of Biological Sciences, Oakland University, Rochester, MI, USA 